\title{
A CONDUÇÃO DE ESTUDOS SEGUNDO A METODOLOGIA DE INVESTIGAÇÃO FENOMENOLÓGICA
}

Magali Roseira Boemer*

A autora apresenta um texto no qual relata sua experiência na orientação de estudos realizados segundo a metodologia de investigação fenomenológica.

Essa experiência engloba processos de orientação em vários níveis: iniciação científica, aperfeiçoamento, mestrado e doutorado. Discorre sobre as fases de uma investigação de tal natureza, ressaltando os pontos críticos e decisivos de cada momento da trajetória metodológica.

Alerta para a importância de o pesquisador realizar um grande investimento no sentido de buscar pelo conhecimento profundo dos fundamentos da fenomenologia, de forma que o estado a ser realizado possa ser conduzido com seriedade, rigor e propriedade gerando, assim, efetivamente, um novo conhecimento.

UNITERMOS: Metodologia de investigação fenomenológica, fenomenologia, metodologia de pesquisa.

Desde de 1985, ainda recém-doutorada, vi-me na situação de orientadora e, como tal, assumindo a responsabilidade de conduzir orientandos pelos caminhos da investigação fenomenológica.

Dessa forma, houve momentos em que a minha trajetória acadêmica se fundia e, às vezes, se confundia com a trajetória dos orientandos e, só agora, decorridos aproximadamente sete anos, está se tornando mais claro para mim o significado dessa experiência. Senti, então, a necessidade de abordá-la por entender que pode se constituir em uma contribuição a

*Professor Livre-Docente do Departamento de Enfermagem Geral e Especializada da Escola de Enfermagem de Ribeirão Preto da Universidade de São Paulo. 
orientadores com competência para conduzir estudos segundo esta metodologia de investigação.

Essa experiência envolve orientandos de vários níveis, quais sejam: alunos de graduação em enfermagem, enfermeiros, mestrandos e doutorandos. Envolve, ainda algumas situações de co-orientação.

Um primeiro ponto que desejo abordar é a forma como o orientador recebe um orientando. Podem ocorrer três tipos de situações: o orientando, geralmente aluno de pósgraduação, conhece a sua linha de investigação e o procura porque deseja realizar o seu estudo segundo esse referencial. Essa é a situação mais desejável, porém não a mais comum, principalmente para alunos de mestrado. O orientando não conhece o orientador mas já conhece alguma coisa da metodologia e por isso o procura. O orientando, ainda candidato à seleção, não conhece o orientador, não conhece a linha de investigação mas o escolhe segundo uma "lista de orientadores", onde, em geral, consta o número de orientandos que cada orientador pode receber. Nesse sentido, pode até haver orientadores mais "cotados ou disputados" e assim, o aluno e orientador acabam se encontrando e, num primeiro momento, nada têm a dizer um ao outro.

Entretanto, essas várias formas de encontro entre orientador e orientando, não diferem muito quanto a natureza de algumas dificuldades iniciais. O que varia é a maior ou menor dificuldade em lidar com elas.

Em se tratando de orientação a nível de Iniciação Científica e Aperfeiçoamento**, o orientador seleciona o bolsista para participar de um projeto. Este aceita ou não participar do projeto do Orientador e, nesse aceite, a possibilidade da bolsa pesa muito mais que 0 próprio tema e/ou linha de investigação. Percebo que esta é uma faceta real no que se refere à essas modalidades de orientação, e que o orientador precisa lidar com ela.

De alguma forma, tenho procurado contornar parte dela ao solidificar que o candidato faça algumas leituras prévias sobre a temática e sobre a questão metodológica numa tentativa de aprendê-lo na sua visão de mundo, no que tem significado para ele. É apenas um recurso que tem dado certo.

Falando dessas orientações em geral (iniciação científica, aperfeiçoamento, mestrado e doutorado) gostaria de ressaltar alguns pontos que carecem de discussão, pois têm se mostrado a mim como relevantes no processo de orientar segundo a metodologia da investigação fenomenológica.

O orientador em fenomenologia tem a propor ao orientado uma linha de investigação, mas

\footnotetext{
**Iniciação Científica - programa do Conselho Nacional de Ciência e Tecnologia (CNPq), destinado à alunos do Curso de Graduação.

Aperfeiçoamento - programa do Conselho Nacional de Ciência e Tecnologia (CNPq), destinado à profissionais não docentes.
} 
ele não tem (e não pode ter) um "problema" para propor ao orientando. Por que não?

Porque em primeiro lugar a investigação fenomenológica não vai partir de um "problema". O pesquisador não terá um problema, mas sim uma interrogação. Quando o pesquisador perguntar ele terá uma resposta. Para MARTINS, BICUDO ${ }^{5}$, o quando o pesquisador interroga terá uma trajetória estará caminhando em direção ao fenômeno, naquilo que se manifesta por si, através do sujeito que experiência a situação.

Quando o pesquisador interroga ele está focalizando o fenômeno e não o fato. A idéia de fato, como é concebida, tem seus fundamentos na lógica e no positivismo clássico que vê o fato como tudo aquilo que pode tornar-se objetivo e rigoroso como objeto da ciência.

Quando há fatos, haverá idéias de causalidade, repetitividade, controle. O pesquisador em fenomenologia segue outro caminho, pois não vai Ter princípios explicativos, teorias ou qualquer definição do fenômeno "a priori". Ele inicia interrogando o fenômeno. Isto não exclui que ele tenha um pensar. Ao recusar os conceitos prévios, as teorias e as explicações a priori já existentes, o pesquisador não parte de um marco zero ou de um vazio. Ele tem um pré-reflexivo. O que precisa evitar é que a teoria influencie o seu interrogar pois, se isso ocorrer, já terá obtido respostas. O interrogar envolve necessariamente um pensar sobre aquilo que estou interrogando. O meu pré-reflexivo é o meu pensar.

O "problema" pressupõe uma expectativa de resposta, de explicação e não é essa a proposta da fenomenologia. O pesquisador tem uma interrogação e vai percorrê-la buscando a sua compreensão. Para isso, o "fenômeno" precisa se apresentar ao pesquisador enquanto fenômeno, ou seja, enquanto algo que pede, que exige um desvelamento, uma "iluminação". Se isso não ocorrer, se o pesquisador não estiver inquieto com algo que está oculto e que quer desocultar, então o fenômeno não está se apresentando a ele enquanto Fenômeno.

Isso nos remete à Segunda consideração. Dado esse fundamento da fenomenologia, fica claro que a interrogação é do pesquisador e não necessariamente do orientador. Ao orientador cabe conduzir o processo, cabe clarear na região de inquérito, mas ele não pode estar igualmente inquieto. Naturalmente que, quando a temática for significante também para o orientador, ele passa a co-habitar essa inquietação. Contudo, em geral, essa pode ser uma primeira dificuldade, ou uma primeira surpresa para o orientando.

Outro ponto que precisa ser analisado, diz respeito à questão do encaminhamento do orientando em termos de percorrer os caminhos da fenomenologia.

Nossa formação básica é na área da saúde e é muito penosa essa incursão por outras áreas que até então não existiam para nós. Ocorre, eu observo, um "momento inicial" de entusiasmo, até de fascinação pelo referencial metodológico. É como se um novo mundo se abrisse, com muitas possibilidades.

Conforme relata MARIANO ${ }^{3}$, a abordagem qualitativa, em geral e, particularmente a fenomenológica, é freqüentemente nova para os alunos e eles tornam-se rapidamente 
entusiasmados. Entretanto, diz a autora, ela não deve ser escolhida simplesmente porque é interessante, diferente e "por não requerer análise estatística", pois ela é um procedimento científico, criativo, que requer um investimento grande, o desenvolvimento do pensamento crítico bem como energia emocional e intelectual.

É preciso um interesse verdadeiro, autêntico, em desvelar o fenômeno, descobrir significados, desenvolver compreensão e explorar o fenômeno na maior diversidade possível.

No momento em que se inicia no estudo, o orientando se assusta porque se depara com um referencial desconhecido, as leituras tornam-se penosas e difíceis, não consegue ler os textos até ao fim, pois são muitos os termos, os vocábulos que não são compreendidos por ele. É um momento particularmente difícil, que o leva à angústia e a forma como ele vai lidar com essa angústia, muitas vezes, é decisiva para o seu prosseguir.

O orientador pode ajudar em parte nesse momento, mas a ajuda que ele pode dar nem sempre é a esperada pelo orientado que precisa percorrer a sua trajetória em direção à compreensão do método e ao que ele se propõe.

Em minha experiência, os meus orientandos de mestrados e doutorado necessariamente cursam disciplinas pertinentes na UNICAMP, UFSCAR, PUC*** São Paulo onde pessoas como Professores: Joel Martins, Aquiles Von Zubben os têm acolhido.

Os alunos necessitam de uma compreensão das bases teóricas da fenomenologia, de seus fundamentos e de seus recursos básicos. O entendimento da fenomenologia quer como movimento filosófico ou como metodologia de investigação (a divisão não é possível), enfim, toda a postura filosófica que sustenta o método pode ser complexa e de difícil compreensão, particularmente para aqueles que têm limitados pré-requisitos de filosofia.

Um curso que apresente e discuta as dificuldades correntes filosóficas, as tradições da ciência, é muito útil, pois familiariza com os axiomas, os pressupostos básicos que geram os vários métodos de investigação.

Sem esta compreensão os alunos tendem a se deter em "como fazer" sem compreender o propósito, o processo e a produção de conhecimento que será gerado.

Entretanto, percebo que, em geral, o orientando se dirige para esses cursos (ou disciplinas) numa expectativa de "aprender a fazer pesquisa segundo a trajetória da fenomenologia" e não se sente correspondido se sua expectativa for a de "um livro de receitas". A pesquisa qualitativa não pode ser abordada como um livro de receitas em que cada passo é especialmente planejado, de forma linear e programada.

Algumas vezes os alunos têm dificuldades em aceitar a dinâmica natural da abordagem de

\footnotetext{
*** UNICAMP - Universidade Estadual de Campinas

UFSCAR - Universidade Federal de São Carlos

PUC - São Paulo - Pontifícia Universidade Católica de São Paulo
} 
pesquisa qualitativa e, freqüentemente, esforçam-se por concretizar cada passo. Assim, este momento pode ser frustrante e essa frustração pode ser amenizada ou aliviada enfatizando-se a flexibilidade inerente ao método e que emerge naturalmente no processo.

MARIANO ${ }^{3}$, ao relatar sua experiência de ensino em cursos de pesquisa qualitativa, refere que tem identificado algumas "habilidades essenciais" requeridas dos estudantes para essa forma de pesquisar. Incluem a habilidade para lidar com ambigüidade, capacidade de abstração e uma "orientação humanística". Os alunos precisam sentir-se confortáveis com a ambigüidade. Apesar de haver um foco de direção, esta abordagem requer flexibilidade de "modelo", tempo para o fenômeno emergir, exploração e descoberta, diferentes percepções e múltiplas realidades, paciência com o inesperado, "insight" para perceber significados no contexto e disponibilidade para aceitar mais do que uma verdade. Outro ponto relevante é a "orientação humanística". Os alunos precisam Ter um genuíno interesse em "ir às pessoas", um desejo de compreender outras perspectivas e uma consciência para ver a relação pesquisador/sujeito como bilateral.

Em relação às habilidades necessárias para conduzir estudos segundo essa trajetória, MARTINS, BICUDO 5 assim se manifestam: "determinar qualidades necessárias como elementos constitutivos para realizar pesquisas qualitativas seria uma agressão à idéia de liberdade da mesma". O meu pensar a pesquisa qualitativa caminha na direção do pensar destes alunos autores.

O que os orientandos necessitam é estar conscientes de suas propensões, tendências e interesses - sua visão de mundo - antes de optar por esta metodologia e estar dispostos a investir no conhecimento requerido.

Quando o pesquisador/aluno passa pelos primeiros momentos desse "impacto" e se "apropria" do referencial da fenomenologia, consegue formular a sua interrogação sobre o fenômeno que quer desvelar ou sobre a faceta que quer desvelar já que o desvelamento total não é possível pela própria fundamentação filosófica do método - relação dialética desvelamento/ocultação. A cada desvelamento há um velamento nele contido.

Nessa "fase" (salientando que não pode ter a conotação positivista de fase enquanto distinta de outra) o que tenho percebido é que o aluno tem tanto mais facilidade quanto mais ele viveu e habitou o mundo "mundo de sua interrogação" e, portanto, ela decorre verdadeiramente do seu pensar e do seu conviver.

Quanto mais o pesquisador conhecer a temática maior é o seu pré-reflexivo e isso Ihe possibilita colocar o fenômeno diante dos seus olhos, em suspensão, e olhar para ele de forma atentiva. Esse olhar atentivo, dirigido para a coisa mesma, que se põe diante do pesquisador para ser experienciada, é o momento da epoche ${ }^{4}$ (suspensão ou parada).

Este não é um momento estático e, nesse sentido, o pesquisador se aproxima e se afasta 
do fenômeno possibilitando a formação clara de sua interrogação. Tenho observado que, quando isso não ocorre, o que se mostra ao orientador é uma "pressa" do orientando em formular sua inquietação como se ela, por si, pudesse lhe abrir as portas para a coleta de dados. Se essa inquietação não for autêntica, a interrogação será artificial e a expectativa de que permita a tão desejada coleta de dados não se concretiza, frustrando o orientando. Não se concretiza porque ele se depara com as dificuldades pertinentes à coleta de dados onde ele vai traçar sua trajetória em direção ao fenômeno.

Para compreensão do fenômeno que foi posto diante dos olhos para a investigação, o pesquisador vai buscar as descrições da experiência pelos sujeitos que estão sendo os sujeitos da pesquisa. Dessas descrições o pesquisador buscará captar a essência.

A descrição se dá, na experiência do sujeito que experiência determinada situação. É dessa maneira, situando-se, que o fenômeno se ilumina e se desvela para o pesquisador.

Em geral, o pesquisador propõe uma questão orientadora para essa descrição.

Aqui, novamente, emerge a vivência do pesquisador com o fenômeno para que ele chegue à formulação da questão orientadora. O seu grau de imersão nos dados, seus valores, crenças e perspectivas podem orientar o foco da investigação para aspectos mais concretos ou concepções mais abstratas.

A interação do pesquisador com o objetivo pesquisado torna-se algo único em cada estudo de natureza qualitativa.

Segundo MARTINS, BICUDO ${ }^{5}$, o ato de descrever algo é dirigido para alguém, ele pressupõe uma audiência. A descrição será tanto melhor quanto mais possibilitar ao leitor ou ao ouvinte, reconhecer o objeto descrito.

A opção pela forma de obter as descrições será do pesquisador dada que estará absolutamente interligada à natureza mesma da investigação. Basicamente, o pesquisador pode recorrer à entrevista, entendida enquanto possibilidade de encontro ou à gravação, sempre com o conhecimento e a anuência dos sujeitos. Pode ocorrer, ainda, a obtenção da descrição por escrito.

O relevante nesse processo é que o orientando precisa aprender a ouvir compreensivamente e a apresentar seus dados de forma descritiva. Ele pode lançar mão de um diário onde vai lançando suas idéias à medida que coleta os dados e aprende, ao lado da linguagem verbal da descrição, as outras formas de discursos (não verbal, gestual, do silêncio). Criará, então, o método de registrar seus dados para articular seu próprio estilo de organizá-los.

O orientando precisa ir entendendo que o ouvir e o perceber o outro de forma compreensiva não se dará da mesma forma em todas as descrições. Graus de compreensão vão ocorrer, coerentemente com a própria fundamentação filosófica que sustenta a investigação. Nesse sentido, o sujeito que descreve é parceiro do pesquisador em seu processo de descoberta. 
No processo de orientação, no mínimo de coleta dos dados tem-se mostrado crítico para o orientando no sentido dele entender que, nesta metodologia, esse não é um momento isolado. A análise desses dados vai ocorrendo de forma simultânea, num constante processo de descobertas.

Segundo ANDRÉ ${ }^{1}$, à medida que a coleta de dados prossegue, as atividades, de análise se orientam para a revisão do conjunto inicial de questões, para a sua reformulação e para a busca de alternativas na interpretação dos dados.

Do exposto, pode-se perceber que a coleta de dados é lenta e o orientando não pode Ter pressa ou ser pressionado. Precisa ter disponibilidade de tempo e, principalmente, disponibilidade pessoal, interior, para um mergulho nos sujeitos. Não haverá um critério amostral que indique que a coleta encerrou-se, critério esse próprio da metodologia das ciências naturais. O critério em fenomenologia é o da repetitividade que expressa o mostrarse do fenômeno em sua essência.

Ao analisar os dados, a primeira questão que se coloca é: o que o pesquisador busca nas descrições? Ele busca o invariante, o que permanece, aquilo que aponta para o que o fenômeno é.

Esse é um outro momento particularmente difícil para o orientando e para o orientador. Quanto maior a vivência do orientando com o tema que está sendo estudado, quanto maior o seu pré-reflexivo, mais ele saberá ler as descrições e dizer do significado nelas contido. Quando o orientador compartilhar do tema ele estará em melhor situação para ajudar o orientando nessa leitura.

Será preciso então, ler através das descrições, dos discursos. Essa leitura inclui mensagens explícitas e implícitas, verbais e não verbais, alternativas e contraditórias. Não haverá um sistema pré-especificado de categorias-tópicos e temas vão sendo gerados a partir do exame dos dados e de sua contextualização no estudo ${ }^{1}$.

Será preciso, também que esses tópicos e temas sejam freqüentemente revistos, reformulados, questionados à medida que a análise de desenvolve, tendo em vista os princípios teóricos e os pressupostos da investigação.

Trata-se sem dúvida, de uma árdua tarefa. No entender de ANDRÉ ${ }^{1}$, esse momento pode ser compartilhado com pessoas que habitam a temática.

Embora os fenomenólogos evitem cuidadosamente o caminho de ditar passos, algum direcionamento pode ser dado quando da análise dos dados. Os estudos de GIORGI $^{2}$, de MARTINS, BICUDO ${ }^{4,5}$, têm nos orientado, particularmente, nesse sentido.

Assim é que esses autores sugerem que a análise de descrição pode ser feita em quatro momentos:

01. O pesquisador lê a descrição inteira, do início ao fim, com vistas a ter um sentido do todo. 
Familiariza-se, então com o texto que descreve a experiência vivida. Procura colocar-se no lugar do sujeito, de forma a não ser um espectador, mas alguém que procura chegar aos significados atribuídos pelo sujeito da mesma forma como ele os atribuiu. Esta "operação" é imperiosa na modalidade fenomenológica.

02. O pesquisador lê a descrição novamente, agora mais lentamente, identificando unidades de significado.

Não há diferenças específicas nessa identificação de unidades de significado, por exemplo, um parágrafo, etc. As condições sob as quais o estudo se desenvolve, o tipo de conhecimento que se busca, os antecedentes e os acontecimentos reais da pesquisa, assim como o envolvimento do pesquisador são todos fatores importantes para justificar porque se seguiu um ou outro caminho.

Emerge novamente um aspecto fundamental, qual seja: - a integração do pesquisador com o pesquisado se torna algo único no estudo de natureza qualitativa. É preciso, então, levar em conta que o processo de categorização do material qualitativo vai envolver não só conhecimento lógico, intelectual, objetivo, mas também conhecimento pessoal, intuitivo, subjetivo, experimental ${ }^{1}$.

Quando o pesquisador apreende unidades de significado ele o faz segundo sua perspectiva (de enfermeiro, de psicólogo) e focalizando o fenômeno que está sendo pesquisado.

Para MARTINS, BICUDO 5 , o pesquisador pinça significados nas descrições. Uma unidade de significado é, em geral, parte da descrição cujas frases relacionam-se umas com as outras indicando momentos. O pesquisador pode, então, solicitar ajuda de outras pessoas que vêem o fenômeno como ele, que vivem o que está sendo pesquisado. Se isso ocorrer, o pesquisador já estará em busca da intersubjetividade.

03. Após obter unidades de significados, o pesquisador percorre todas as unidades identificadas e expressa o significado contido nelas. Isso é particularmente verdadeiro para as unidades mais reveladoras do fenômeno considerado.

Uma questão relevante que surge aqui é quanto à existência de critérios para determinar o grau de importância ou relevância de um tópico. Está implícito que um critério é a freqüência com que ocorre, mas não é único. No entender de $\mathrm{ANDRE}^{1}$, é possível que os dados contenham aspectos, observações, comentários, características únicas, mas extremamente importantes para uma apreensão mais abrangente do fenômeno estudado. Haverá também mensagens não intencionais, implícitas e contraditórias, que, embora únicas, revelam dimensões importantes da situação.

A questão é, pois, encontrar maneiras de poder detectar essas informações singulares, mas relevantes e poder distinguí-las de outras também singulares, mas irrelevantes.

Nesse sentido, a intuição e a subjetividade têm um papel fundamental no processo de localização desse tipo de dado, além, evidentemente, do quadro teórico no qual o estudo se 
situa $^{1}$. Cada pesquisador tem perspectivas, propósitos, experiências anteriores, valores e maneiras de ver a realidade e o mundo de forma que, ao interagir com o objeto pesquisado, orienta o seu foco de atenção para problemas específicos, determinadas mensagens, aspectos particulares.

Se, por um lado, atenta ANDRÉ ${ }^{1}$, devem existir métodos para tratar dos dados qualitativos, por outro é necessário o reconhecimento e valorização do papel da intuição e da subjetividade no processo de selecionar, categorizar e interpretar as informações.

04. Finalmente, o pesquisador sintetiza as unidades de significado para chegar à estrutura do fenômeno e à sua essência, Nessa síntese, o pesquisador integra os "insights" contidos nas unidades de significado transformadas em uma descrição consistente da estrutura do fenômeno.

Alguns pesquisadores usam a palavra categoria para essa síntese, entendida enquanto tema. Tematizar significa tomar seriamente e estudar de forma sistemática um assunto.

Um ponto importante a ser dito é que, em todos os momentos, os dados precisam ser examinados, questionados amplamente de forma a ajudar o pesquisador a manter o foco de atenção no todo, sem perder de vista a multiplicidade de sentidos que podem estar implícitos no material.

"O que isso tudo quer dizer?", "Quais suas mensagens?", são questões que o orientador e orientando precisam fazer incessantemente para possibilitar uma visão profunda e multidirecional dos fenômenos, principalmente se forem levados em conta o contexto dos dados e o quadro teórico em que se situa o fenômeno estudado.

Fundamentalmente, o que se procura obter num estudo é a compreensão do objetivo focalizado. No momento de análise, a minha experiência tem mostrado que o orientador precisa estar próximo, mas precisa, sobretudo permitir que o orientado crie suas próprias estratégias. Tenho possibilitado, então, momentos de aproximação e de afastamento de forma a facilitar essa atribuição de significados, sem prejuízo do rigor metodológico.

É uma fase que tem se mostrado muito gratificante ou muito geradora de conflitos. Quanto maior o preparo e a imersão do orientando com a postura fenomenológica, tanto melhor ele tem percorrido esse momento. O conflito pode surgir se o orientando esperar do orientador algo que ele não pode fazer: a interpretação dos dados. O orientador pode, somente, orientar metodologicamente esse momento.

Há que se dizer, ainda, que os significados que o pesquisador pode detectar nas descrições têm como referência a totalidade das experiências vividas pelo sujeito e essa totalidade vai além da consciência explicitada pelo sujeito. Dessa forma, haverá sempre uma região não expressa que permanece oculta. Por isso, a pesquisa sempre prossegue.

Ao relatar seu estudo, o pesquisador assumirá o seu "eu" e a redação é feita na primeira pessoa do singular. No início o orientando estranha. Se o estudo for conjunto, usamos a primeira pessoa do plural. 
Ao divulgar aos seus pares um estudo conduzido segundo o referencial fenomenológico, o pesquisador pretende estabelecer a intersubjetividade, pois, segundo esse referencial, é através dela que se chega à objetividade.

Trata-se de uma objetividade a ser obtida em perfis, em perspectivas. O pesquisador terá em mente que a pesquisa sempre prossegue, nunca estará concluída, pois haverá sempre novas verdades a serem desocultadas.

Meu conviver com meus orientados da área de enfermagem tem me mostrado que eles, num primeiro momento, identificam-se com a metodologia de investigação fenomenológica dado que a enfermagem, por lidar com o humano, dele se aproxima de uma forma ímpar e a proposta de fenomenologia é muito pertinente ao seu cotidiano vivencial. Assim, produzir conhecimentos segundo essa forma de investigação faz sentido para os orientandos enfermeiros.

Por outro lado, entretanto, a formação que têm para pesquisa fundamenta-se na metodologia das ciências naturais e o que tenho visto é que o orientando fica em conflito entre duas possibilidades:

- A de fazer pesquisa segundo o método que já conhece, que tem uma tradição e, portanto, uma garantia de aprovação pela comunidade científica, muito embora sua interrogação indique outra trajetória;

- A de pesquisar outro caminho, ainda desconhecido, mas que the surge como possibilidade de estudar o seu objeto da forma que faz sentido para ele.

Seguir o segundo caminho implica, a meu ver, em correr riscos e isso precisa ser colocado ao orientado. A decisão será dele e precisa ser dele.

O que considero extremamente relevante e que desejo explicar ao encerrar minha reflexão é a certeza que tenho que não existe melhor caminho. São caminhos diferentes e que precisam ser bem percorridos por cada um com sua abordagem metodológica.

É o caminho que faz sentido para o pesquisador e que lhe dá a grata satisfação de contribuir para o avanço do conhecimento. Cada método dá conta de uma parte desse todo e nenhuma metodologia, por si, traz respostas finais à toda complexidade do ser humano.

Por isso acredito firmemente que fomentar atritos e conflitos metodológicos nada acrescenta ao avanço da enfermagem como um todo e significa, no mínimo, retrocesso e um desgaste desnecessários. Esta mensagem, com toda a clareza como a vejo, tenho procurado transmiti-la aos meus orientandos.

Na fase de revisão deste texto, ocorreu a morte do professor Joel Martins ${ }^{\star \star \star \star}$, várias vezes mencionado nas referências bibliográficas. Não poderia deixar de mencionar tal fato num

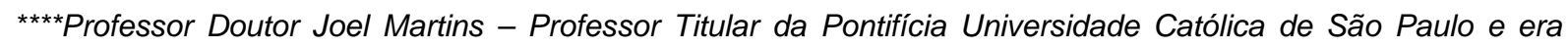
Reitor desta Universidade. Faleceu em 03 de maio de 1993.
} 
artigo em que relato minha experiência em conduzir estudos segundo a metodologia de investigação fenomenológica. A ele devo o processo de descoberta dessa forma de produzir conhecimento. A ele devo o acolhimento aos meus orientandos. Ao Prof. Joel Martins, devo fundamentalmente, o encontro de um novo horizonte para o meu existir acadêmico.

The author reports on her experience as an adviser in studies carried out according to the methodology of a phenomenological investigation.

This experience involves advising processes at several levels: scientific initiation, scientific training, masters and doctorate. The phases of investigation of this type are discussed, with emphasis on the critical and decisive points along the methodological pathway.

Emphasis is placed on the importance of a significant investment in the search for an in-depth understanding of the principles of phenomenology on the part of researchers, so that the study to be performed will be conducted in a serious, rigorous and appropriated manner, thus effectively generating new knowledge.

UNITERMS: Methodology of phenomenology investigation, phenomenology, research methodology

La autora presenta un texto en el cual relata su experiencia en la orientación de estudios realizados según la metodología de investigación fenomenológica.

Esa experiencia engloba procesos de orientación en varios niveles: iniciación científica, perfeccionamiento, maestría y doctorado. Discurre sobre las etapas de una investigación de tal naturaleza, resaltando los puntos críticos y decisivos de cada momento de la trayectoria metodológica.

Alerta para le importancia del pesquisidor realizar un grande investimento en el sentido de buscar por el conocimiento profundo de los fundamentos de la fenomenológica, de manera que el estudio a ser realizado pueda ser conducido con seriedad, rigor y propiedad produciendo así, con efectividad, un nuevo conocimiento.

UNITERMOS: Metodología de investigación fenomenológica, fenomenologia, metodología de investigación

\section{REFERÊNCIAS BIBLIOGRÁFICAS}

01. ANDRÉ, M. E. D. A. Texto, contexto e significativos: algumas questões na análise de dados qualitativos. Caderno de Pesquisa, São Paulo, n. 45, p. 66-71, maio 1983. 
02. GIORGI, A. Phenomenology and psychological. Pittsburgh: Duchisne University Press, 1985.

03. MARIANO, C. Qualitative research instructional strategies and curricular considerations. Nursing Health Care, v. 11, n. 7, p. 354-59 1990

04. MARTINS, J., BICUDO, M. A. V. Estudos sobre existencialismo, fenomenologia e educação. São Paulo: Moraes, 1983.

05. MARTINS, J., BICUDO, M. A. V. A pesquisa qualitativa em psicologia: fundamentos e recursos básicos. São Paulo: Moraes, 1989. 